\title{
REVIEW
}

\section{Vasculitides as a rare cause of intermittent claudication}

\author{
Celecova Z, Krahulec B, Lizicarova D, Gaspar L \\ 2nd Department of Internal Medicine, Comenius University Hospital, Bratislava, Slovakia. \\ zuzana.celecova@gmail.com
}

\begin{abstract}
Intermittent claudication of the lower extremities is a common symptom described in older patients with atherosclerotic peripheral arterial disease. Peripheral arterial disease due to atherosclerosis is known to be associated with a higher risk of myocardial infarction, stroke and all-cause mortality. However, if intermittent claudication appears in a younger group of patients or older patients in absence of traditional risk factors for atherosclerosis such as smoking, dyslipidemia, arterial hypertension and diabetes mellitus other causes than atherosclerosis must be considered. These conditions include vasculitides, fibromuscular dysplasia, cystic adventitial disease, excentric vascular compression by tumor, popliteal artery entrapment syndrome, trauma or dissection. Vasculitides present a heterogenous group of disorders characterized by inflammatory destruction of blood vessels. Although often not a leading symptom intermittent claudication could be a part of a clinical picture in giant-cell arteritis, Takayasu's arteritis, Buerger's disease, polyarteritis nodosa or Behçet disease. Limb claudication is usually of rapid onset, progressive and bilateral. Each of the mentioned vasculitides is specific in ethiology and clinical manifestation with a variable prognosis for the patient. Increased awareness of the presence of different causes of limb claudication and their early diagnosis with a prompt initiation of appropriate treatment may help to avoid clinical progression that can lead to vascular surgery or even limb loss (Ref. 37). Full Text in PDF www.elis.sk.

Key words: intermittent claudication, giant-cell vasculitides, variable clinical picture.
\end{abstract}

Intermittent claudication of the lower extremities is a common symptom described in older patients with atherosclerotic peripheral arterial disease (PAD). It is defined as a typical pain that appears in leg while walking (at a level below arterial obstruction), forces the patient to stop and disappears at rest, usually within 3-4 minutes. It's usually bilateral, isolated claudication pain is rare (1). In Fontain's classification of PAD intermittent claudication presents II. stade and is divided into 3 subcategories regarding the distance before claudication pain starts (more than $200 \mathrm{~m}$, less than $200 \mathrm{~m}$ or less than $50 \mathrm{~m}$ ) (2).

Prevalence of atherosclerotic PAD is estimated to be up to $29 \%$ in adult population (3), with frequency strongly related to age uncommon before 50 years, rising gradually at older ages (1). Its presence is known to include not only lower extremities leading to decreased mobility or even limb loss but is highly associated with an increased risk of premature myocardial infarction, stroke and all-cause mortality (4).

However, if intermittent claudication appears in younger patients or in older patients in absence of traditional risk factors for atherosclerotic disease such as smoking, dyslipidaemia, diabetes mellitus and arterial hypertension other causes than atherosclerosis must be considered. These conditions include primary or

2nd Department of Internal Medicine, Comenius University Hospital, Bratislava, Slovakia

Address for correspondence: Z. Celecova, MD, 2nd Department of Internal Medicine, Comenius University Hospital in Bratislava, Mickiewiczova 13, SK-813 69 Bratislava, Slovakia.

Phone: +421.2.57290329, Fax: +421.2.57290785 secondary vasculitides, fibromuscular dysplasia, cystic adventitial disease, excentric vascular compression by tumor e.g. osteochondroma, popliteal artery entrapment syndrome, trauma or dissection. Thrombosis or emboli of lower extremity artery usually lead to acute limb ischaemia rather than chronic limb ischaemic complications $(4,5)$.

Vasculitides refer to a heterogenous group of disorders that are characterized by inflammation and necrosis of blood vessels - both arteries and veins. Various attempts of classification and nomenclature of vasculitides have been proposed taking as a distinguishing feature either the underlying cause (idiopathic or secondary to systemic diseases, infection, drug abuse, medication, malignity, radiation, transplantation, etc.) or location of the affected vessels or type or size of vessels that are predominantly affected (6). The least classification mentioned thus categorises vasculitides of small, medium and large caliber. It also must be mentioned that overlap syndromes can occur giving more variable clinical picture (6).

The large-vessel vasculitides include giant-cell arteritis (GCA) also known as temporal arteritis and Takayasu's arteritis. Some authors count also polymyalgia rheumatica (PMR) into this group of vasculitides as they regard it as one clinical entity with GCA. Medium sized vasculitides manifest mainly as polyarteritis nodosa, cutaneous PAN and Kawasaki disease. The small-vessel category refers to Wegener's granulomatosis, Churg-Strauss syndrome, microscopic polyangiitis, the leukocytoclastic vasculitides such as Henoch-Schönlein purpura and isolated cutaneous leukocytoclastic vasculitis. There are in addition vasculitides affecting various- sized vessels, such as Behçet disease or Buerger's disease (6). 
353-356

In the following review we focused on some vasculitides that have been described to be associated with limb claudication in more or lesser extent.

\section{Giant-cell arteritis}

Giant-cell arteritis (GCA) is a primary systemic vasculitis mainly affecting large vessels of distal aortic arch, predominantly the cranial arteries, especially the superficial temporal artery and the arteries supplying the optic nerve (7). Aortic aneurysm, dissection and large vessel stenoses are well known serious vascular complications of GCA and are present in almost one-third of patients (8). Until recently not many studies described presence of lower extremity involvement in GCA and its consequences, in general it was thought to be a rare manifestation (9). However recent studies using ultrasonography and positron emission tomography (PET) demonstrated that prevalence of lower extremity involvement is probably underestimated and proved vasculitic changes in lower extremities in a significant proportion of patients with GCA, although most of them were asymptomatic $(10,11,12)$. Patients with PMR were shown to be at a higher risk of developing lower extremity claudication and clinical PAD even in absence of symptoms of GCA or positive temporal artery biopsy $(13,14)$. Recent retrospective study lead by Czihal and his colleagues came with a little different regard on severity of lower extremity GCA. Authors focused on patients with GCA and used color duplex sonography to evaluate extent of lower extremity vasculitis. GCA of femoropopliteal arteries was present in half of the patients, developed bilaterally and every second patient with positive sonography finding was symptomatic either in means of claudication or symptoms of critical limb ischemia. In contrast to atherosclerotic etiology, ischemic symptoms in patients with GCA progressed rapidly and lead to development of limb-threatening ischemia within very short of time (15). Assie and his colleagues came up with similar results demonstrating a common presence of upper and lower extremity involvement in GCA even in early phase of disease (16). According to published cases prognosis of limb involvement is quite variable, patients with critical limb ischemia frequently undergo revascularisation treatment. Claudication can be managed by conservative treatment in most cases, but severe deterioration leading to even limb amputation is also a threat $(16,17,18)$. Some studies using ultrasound also found quite a frequent presence of atherosclerotic plaques in lower extremity arteries in patients older than 50 years $(15,19)$. Atherosclerosis must be recognised as a possible co-factor in elderly but if acute bilateral and rapidly progressive claudication occurs especially in association with a systemic inflammatory disorder of unknown origin suspicion for possible extracranial GCA must be taken into consideration $(15,17)$. Cranial symptoms or systemic features of GCA are often very mild or absent $(15,20)$.

\section{Takayasu's arteritis}

Takayasu's arteritis also known as pulseless disease or occlusive thromboaortopathy is a systemic vasculitis affecting large ves- sels, predominantly aorta and its branches. It mainly affects young or middle-aged women less than 40 years old (21). Manifestations range from asymptomatic disease to symptoms reflecting ischemia of end-stage organ. The disease has usually 2 clinical stages - the first one is characterized by non-specific systemic symptoms, followed by the occlusive phase with consequences in means of cerebral, myocardial, limb ischemia, retinopathy, renovascular or pulmonary hypertension. Limb ischemia is manifested as claudication predominantly in upper limbs but affects lower limbs as well $(21,22)$. Non-invasive examination such as decreased brachial artery pulse, blood pressure difference between arms of more than $10 \mathrm{mmHg}$ or bruits over subclavian arteries or aorta should be a part of evaluation process in considering Takayasu's arteritis $(21,23)$.

\section{Buerger's disease}

Thromboangiitis obliterans (TAO) or Buerger's disease is a rare systemic vasculitis characterized by occlusive segmental and multiple inflammatory lesions of small and medium-sized arteries and superficial veins especially of upper and lower extremities (24). It predominantly occurs in young males with a strong link to history of past or current tobacco consumption, only less than $5 \%$ are nonsmokers (25). Clinical picture of TAO is quite different from either atherosclerosis or other vasculitides posting this disease into a specific category of vasculitides (24). The commonest presenting symptoms are ischaemic manifestations of lower and upper extremities. Patients may present with claudication in the arch of the foot, hands, with later onset of rest pain and ischemic ulcerations and gangrene on the toes, feet and fingers. As the disease progresses (more central to the body) claudication in the calf of thigh may develop. Patients with obliterations in femoropopliteal regions have in almost all cases infrapopliteral obliterations as well (24). In one study lead by Stvrtinova and her colleagues intermittent claudication was a symptom present in almost $73 \%$ of patients with TAO (26). Other signs and symptoms of TAO include superficial thrombophlebitis that could be migratory and recurrent, numbness and tingling of the digits, paresthesia, Raynaud's phenomenon $(24,25,27)$. Systemic signs and symptoms are often rare, except for rheumatic manifestations. Up to $12.5 \%$ of patients with TAO present with intermittent migratory arthritis of large joints accompanied by local signs of inflammation, these manifestations may precede diagnosis of TAO by 10 years (28).

Diagnosis of TAO is rendered difficult for the lack of specific subjective symptoms, objective signs, radiological and laboratory findings, the specificity of histopathological evidence as well as the lack of internationally accepted and well defined diagnostic criteria (25).

In case of feet claudication physical examination including measurement of ankle-brachial index could be normal and thus diagnosis of Buerger' s disease is often made only when distal ischemic ulcers and gangrene appear and further diagnostic approach is fulfilled $(24,25)$.

\section{Polyarteritis nodosa}

Polyarteritis nodosa (PAN) is a rare systemic necrotizing vasculitis involving medium and small muscular arteries affecting 
multiple organs - skin, joints, peripheral nerves, the gut and the kidney, usually sparing the lungs and the venous system. This refers to a classic type of PAN. Microscopic polyangiitis (MPA) is an ANCA-associated systemic vasculitis that has similar features of classic PAN with the additional involvement of capillaries, arterioles and venules, affecting renal glomeruli and pulmonary capillaries $(29,30)$. PAN can manifest as a variable clinical entity, can be progressively fatal, resistant to therapy or present as a less severe slowly progressive form (29). Patients usually present with non-specific systemic symptoms and symptoms of ischemia of almost any organ except for lungs. Arthralgias, myalgias, neuropathy, cutaneous manifestations or gastrointestinal symptoms are common findings. To date not many cases with PAN associated with peripheral vascular disease have been published. Although not typical, bilateral limb claudication and symmetrical peripheral gangrene were described as a presenting feature of PAN in some patients $(31,32,33,34)$. These rare cases outline the variable and unexpected clinical picture of PAN. As this disease could be a life threatening a prompt diagnosis in essential in order to start the appropriate treatment.

\section{Behçet disease}

Behçet disease is a rare chronic systemic vasculitis that presents with recurrent mucose membrane ulceration and ocular involvements. It can also involve gastrointestinal and pulmonary tract, musculoskeletal and neurological systems $(35,36)$. Vascular involvement, usually superficial thrombophlebitis and deep vein thrombosis are common manifestations. Arterial involvement is supposed to be less common, however more dangerous in outcome - aneurysm and occlusions of large arteries have been described as a major complication significantly increasing mortality (37). In an autopsy material of up to $37 \%$ patients with Behçet disease large artery aneurysm and occlusions were described, some patients clinically presented with intermittent claudication (35). Ugurlu and colleagues found in their study focused on cardiovascular complications in patients with Behçet disease that intermittent claudication was more common among patients with vascular disease especially those with lower extremity deep vein thrombosis. After excluding patients with vascular diseases no difference in presence of CI was found between patients with Behçet disease and a control group. In this case authors interpret more frequent $\mathrm{CI}$ as a cause of venous insufficiency rather than a cause of atherosclerosis (23).

\section{Conclusion}

The aim of this review was to focus on vasculitides as a rare cause of limb claudication. Atherosclerosis is known to be a major ethiologic factor leading to symptoms of peripheral arterial disease. However if bilateral leg claudication of recent onset in adult population especially young patients in absence of traditional risk factors for atherosclerosis occurs other non-atherosclerotic conditions must be considered $(1,4,5)$. Vasculitides are one of the possibilities. From the reviewed literature limb claudication is a clinical feature in giant-cell arteritis, Takayasu's arteritis, Buerger's disease, polyarteritis nodosa or Behçet disease. Their clinical picture is quite diverse what makes the diagnosis of vasculitis often complicated. They must be however taken into consideration concerning limb claudication in order to prevent or minimize deterioration to critical limb ischemia or even limb loss.

\section{References}

1. ESC Guidelines on the diagnosis and treatment of peripheral artery diseases. Eur Heart J 2011; 32: 2851-2906.

2. Štvrtinová V. Princípy diagnostiky PAO končatín. 175-179. In: Štvrtinová V et al (Eds). Choroby ciev. Bratislava: SAP, 2008.

3. Weinberg I, Jaff MR. Nonatherosclerotic arterial disorders of the lower extremities. Circulation 2012; 126: 213-222.

4. Odporúčania pre diagnostiku a liečbu periférneho artériového ochorenia končatín. Vask Med 2010; 2 (S2).

5. Sutcliffe JB, Bui-Mansfield LT. AJR Teaching File: Intermittent claudication of the lower extremity in a young patient. AJR 2007; 189: 17-20.

6. Štvrtinová V, Rovenský J, Jakubovský J et al. Klasifikácia a etiopatogenéza vaskulitíd. 553-563. In: Štvrtinová V et al (Eds). Choroby ciev. Bratislava, SAP, 2008.

7. Rovenský J, Leeb BF, Bird H et al: Polymyalgia Rheumatica and Giant Cell Arteritis. Bratislava: SAP, 2007. 1-91.

8. Nuenninghoff DM, Hunder GG, Christianson TJ et al. Incidence and predictors of large-artery complications (aortic aneurysm, aortic dissection, and/or large-artery stenosis) in patients with giant cell arteritis: a population-based study over 50 years. Arthritis Rheum 2003; 48: 3522-3531.

9. Lie JT. Aortic and extracranial large vessel giant arteritis: a review of 72 cases with histopathologic documentation. Semin Arthritis Rheum 1995; 24: 422-431.

10. Blockmans D, de Ceuninck L, Vanderschueren S et al. Repetitive 18F-fluorodeoxyglucose positron emission tomography in giant cell arteritis: a prospective study of 35 patients. Arthritis Rheum 2006; 55: 131-137.

11. Aschwanden M, Kesten F, Stern $M$ et al. Vascular involvement in patients with giant cell arteritis determinded by duplex sonography of $2 \times 11$ arterial regions. Ann Rheum Dis 2010; 69 (7): 1356-1359.

12. Schmidt WA, Natusch A, Moller DE et al. Involvement of peripheral arteries in giant cell arteritis: a color Doppler sonography study. Clin Exp Rheumatol 2002; 20: 309-318.

13. Moosig F, Czech N, Mehl C et al. Correlation between 18-fluorodeoxyglucose accumulation in large vessels and serological markers of inflammation in polymyalgia rheumatica: a quantitative PET study. Ann Rheum Dis 2004; 63: 870-873.

14. Blockmans D, Maes A, Stroobants $S$ et al. New arguments for a vasculitic nature of polymyalgia rheumatica using positron emission tomography. Rheumatology 1999; 38: 444-447.

15. Czihal M, Tato F, Rademacher A et al. Involvement of the femoropopliteal arteries in giant cell arteritis: clinical and color duplex sonography. J Rheum 2012; 39: 1-8.

16. Assie C, Janvresse A, Plissonnier D et al. Long-term follow-up of upper and lower extremity vasculitis related to giant cell arteritis: A series of 36 patients. Medicine 2011; 90: 40-51. 
$353-356$

17. Le Hello C, Levesque $\mathbf{H}$, Jeanton $\mathbf{M}$ et al. Lower limb giant cell arteritis and temporal arteritis. Followup of 8 cases. J Rheum 2001; 28: 1407-1412.

18. Kermani TA, Matteson EL, Hunder GG et al. Symptomatic lower extremity vasculitis in giant cell arteritis: A case series. J Rheum 2009; 36: $2277-2283$.

19. Gonzales - Juannatey C, Lopez-Diaz MJ, Martin J et al. Atherosclerosis in patients with biopsy-proven giant cell arteritis. Arthritis Rheum 2007; 57: 1481-1486.

20. Tsai TY-E, Massasso D, Sharma $P$ et al. Taking PET for a walk - an unusual cause of bilateral leg claudication. J Rheumatol 2010; 37: 877-879.

21. Štvrtinová V, Vacula I. Takayasuova arteritída. 569-574. In: Štvrtinová V et al (Eds). Choroby ciev. Bratislava: SAP, 2008.

22. Johnston SL, Lock RJ, Gompels MM. Takayasau arteritis: a review. J Clin Pathol 2002; 55: 481-486.

23. Ugurlu S, Seyahi E, Yazici H. Prevalence of angina, myocardial infarction and intermittent claudication assesed by Rose Questinnaire among patients with Behçet's syndrome. Rheumatology 2008; 47: 472-475.

24. Štvrtinová V, Labaš $\mathbf{P}$, Štvrtina $\mathbf{S}$ et al. Thrombangiitis obliterans. 584-595. In: Štvrtinová V et al (Eds). Choroby ciev. Bratislava: SAP, 2008.

25. Puéchal X, Fiessinger JN. Thromboangiitis obliterans or Buerger's disease: challenges for the rheumatologist. Rheum 2007; 46: 192-199.

26. Štvrtinová V, Ambrózy E, Štvrtina $\mathbf{S}$ et al. 90 years of Buerger's disease - what has changed? Bratisl Lek Listy 1999; 100 (3): 123-128.

27. Arkkila PE. Thromboangiitis obliterans (Buerger's disease). Orphanet J Rare Dis 2006; 1: 14.
28. Puéchal X, Fiessinger JN, Kahan A et al. Rheumatic manifestations in patients with thromboangiitis obliterans (Buerger's disease). J Rheumatol 1999; 26: 1764-1768.

29. Štvrtinová V, Rovenský J, Jakubovský J. Nodózna polyarteritída a mikroskopická polyangiitída. 597-603. In: Štvrtinová V et al (Eds). Choroby ciev. Bratislava: SAP, 2008.

30. Pettigrew HD, Teuber SS, Gershwin ME. Polyarteritis nodosa. Compr Ther Fall 2007; 33 (3): 144-149.

31. Fred HL et al. Images in cardiovascular medicine. Polyarteritis nodosa inducing symmetric peripheral gangrene. Circulation 2003; 107 (22): 2870.

32. b Symmetric peripheral gangrene as an emerging manifestation of polyarteritis nodosa. J Rheumatol. 2007; 34 (2): 440-441.

33. Heron E, Fiessinger JN, Guillevin L. Polyarteritis nodosa presenting as acute leg ischemia. J Rheumatol 2003; 30 (6): 1344-1346.

34. De Golovine S, Parikh S, Lu L. A case of polyarteritis nodosa presenting initially as peripheral vascular disease. J Gen Intern Med 2008; 23 (9): 1528.

35. Bečvář R, Rovenský J. Behcetova choroba. 629-630. In: Štvrtinová V et al (Eds). Choroby ciev. Bratislava: SAP, 2008.

36. Kovačova E, Salmas J, Stenova $\mathbf{E}$ et al. Behçet's syndrome. Bratisl Lek Listy 2005; 106 (12): 386-389.

37. Yazici H, Esen F. Mortality in Behçet's syndrome. Clin Exp Rhematol 2008; 26 (Suppl 51): 138-140.

Received February 19, 2013. Accepted March 29, 2013. 